\title{
Dead Memories: Heidegger, Stiegler, and the Technics of Books and Libraries
}

\author{
DAVID TKACH
}

This experience of individuals inherited by other individuals is what I call the world, the world inasmuch as it is always inhabited by spirits. (Stiegler, "Technics of Decision: An Interview”)

The advent of printing is thus a major transformation of the orthographic epoch of the already-there. (Stiegler, Technics and Time, Vol. 2: Disorientation)

In the writings of Bernard Stiegler, one of his most striking critiques of Martin Heidegger is that throughout the multifaceted investigations of technology, from Being and Time to "The Question Concerning Technology," Heidegger does not address the inherently technological character of the way in which particular languages or traditions, what may be called the content of humanity's historicity, are handed down (überliefern) to human beings. In this paper, I hold Stiegler's critique to provide the basis for a possible supplement to Heidegger's examination of history, memory, and technology. This supplement is necessary because for Stiegler a philosophical examination of the structures of history and memory, for it to be completely accurate concerning the phenomena it purports to describe, must examine the process by which history and memory is transmitted and preserved. This process can only be understood through the subsequent examination of particular technological artifacts temporally specific to the particular historico-temporal moments of that transmission and preservation. Stiegler's critique 
thus encourages a rereading of Heidegger's statements concerning technology and technological artifacts in light of this supplement.

I propose that one way of more clearly understanding this supplement is to anchor a discussion of it to the concepts of the modern library and the printed books housed there. ${ }^{1}$ I do this for two reasons. The first is that it is a commonplace to speak of books and the institutions that permit access to them, libraries in particular, as the means by which, among other things, the thoughts of the author can be accessed by successive generations of readers. As such, it would seem that an examination of the process of history and memory's transmission and preservation would naturally begin with the book and the library. The second, if we begin to think more like Heidegger, is that the book considered as an artifact situated in a particular time and place can be understood to echo the structure of the temporality of Dasein conceptually, in the sense that a book is a thing present before the reader, written and published in the past, and imbued by the author with the intent of being read in the future. Books as artifacts permit the reader to, quite literally, have contact with the work and experiences of human beings no longer alive, and are, at least for the moment, still the primary means by which we learn of and from the past. ${ }^{2}$ A detailed examination of Heidegger's various mentions of books and libraries, which I will conduct below, shows how important an examination of particular technological artifacts is for anchoring the philosophical examination of history and memory's transmission and preservation to the particular technological means by which that transmission and preservation occurs.

In this paper, I examine three exemplary texts, from the beginning, middle, and end of Heidegger's career, in order to understand how one can construe the book and the library as technological artifacts in the context of Heidegger's thought. Before this, however, I wish to set the stage via a discussion of Stiegler's work, especially his critique of Heidegger found in 
Technics and Time, in greater detail. I especially wish to emphasize in Stiegler's work the relation between living, internal human memory, and nonliving, external means of preserving that memory. For Stiegler, as for Heidegger, the concept of death figures prominently in philosophy, and I hope to show how each thinker understands this concept. After my discussion of Heidegger's writings conducted in light of Stiegler's critique, I conclude with a brief recapitulation of Stiegler's thinking in light of David Mitchell's novel, Cloud Atlas. I believe that this novel's content and structure can be understood as a representative illustration of Stiegler's conceptual framework concerning dead memory and its claim upon the living.

The guiding theme in this paper-the book and the library understood as technological artifacts - is found in the thoughts of the figure to whom both Heidegger and Stiegler respond, critique, draw from, or to borrow Stiegler's phrase, philosophize "right up against" ("Technics of Decision" 156): Plato. In the Phaedrus, in the midst of describing an Egyptian myth concerning the invention of writing, Plato calls it a "potion [pharmakon] for memory and intelligence" (Phaedrus 68). Plato goes on to claim that writing

will atrophy people's memories. Trust in writing will make them remember things by relying on marks made by others, from outside themselves, not on their own inner resources, and so writing will make the things they have learnt disappear from their minds. Your invention is a potion for jogging the memory, not for remembering. (69)

Plato thus appears to be privileging speech over writing, in the sense that those who strive to be wise, the philo-sophoi, will not depend on the writing of others, understood as artificial and hence technical, to remember the knowledge they accumulate, but instead will strive to be able to remember solely from their own powers.

The first and obvious problem with Plato's claim concerning writing is that Plato wrote it, in the form of the Greek text called Phaedrus, which we now have in front of us (in English 
translation, in my case). ${ }^{3}$ Putting this problem, as well as the attendant problem of this critique of writing being presented in the context of an Egyptian myth in the dialogue, to one side, it is important to begin by noting the inherent ambiguity of the term pharmakon, which Derrida says can mean "both remedy and poison" (Dissemination 70). Writing has a dual (and ambiguous) quality. The two concepts mentioned by Plato at this point in the dialogue, for which writing has respectively different effects, are internal, individual memory possessed by human beings (mneme), and those things or objects external to human beings which help memory (hypomnesis). The pharmakon of writing, for Derrida, is "a debilitating poison for memory (mneme), but a remedy or tonic for its external signs" (110), that is, for hypomnesis. Thus, Derrida interprets Plato to hold that there is an "opposition" (111) between mneme and hypomnesis, between the internal memory of an individual and the external memory aids, e.g., books, which are held to weaken the ability of that internal memory.

Discussing the same passage, Heidegger notes a similar opposition between mneme and hypomnesis: they are "essentially different," as mneme is "a going back, a repetition and appropriation of the matters themselves," while hypomnesis "is a mere reminder, one that adheres to the spoken word" (Plato's Sophist 237). It is in the midst of this discussion that Heidegger also notes the association of mneme with sophias aletheia ('wise truth') and hypomnesis with doxa, ('public opinion') (237), lost in the English translation quoted earlier. ${ }^{4}$ Heidegger here does not comment on nor critique Plato's bifurcation of memory and external aids to memory - of which writing, and, one may conclude, books, are examples. However, turning back to Derrida, we are to understand that it is the sophist, the figure associated with opinion and often functioning in Plato as the antithesis or mirror image of the philosopher striving for truth (aletheia), who "sells the signs and insignia or science: not memory itself 
(mneme), only monuments (hypomnemata), inventories, archives, citations, copies, accounts, tales, lists, notes, duplicates, chronicles, genealogies, references" (Dissemination 107; see 67). For Derrida, Plato equates the buying and selling of the sophist's writing as somehow false or fallen, in comparison to internal exercise of the philosophical mneme, ultimately expressible through self-created speech.

Derrida's presentation of Plato as privileging speech over writing - the beginning point, in Derrida's view, of the inherently logocentrist tendencies of all philosophy since Plato-is important to consider in greater detail, but not for the purposes of this paper. Instead, I wish to follow the development of the concepts of mneme and hypomnesis through their appearance in the writings of Derrida's student, Stiegler. Stiegler follows Derrida's interpretation of those concepts as signposts of his own understanding of technology - though of course in a way at odds with Plato's use of them. ${ }^{5}$

\section{Stiegler's Concepts: Epiphylogenesis, Hypomnesis, Mnemotechnics}

In order to arrive at a satisfactory understanding of Stiegler's critique of Heidegger, it will be necessary to define several terms that appear in Stiegler's writings which finally hang together in relation to one of Stiegler's most important concepts: epiphylogenesis. Stiegler identifies three types of memory: "genetic memory; memory of the central nervous system (epigenetic); and techno-logical memory (language and technics are here amalgamated in the process of exteriorization)" (Stiegler, Technics and Time Vol. 1, 177). This third form of memory is called epiphylogenetic, as it is comprised of the content of epigenetic, or individual, memory and at the same time "the phylogenetic support for the accumulation of knowledge that constitutes the intergenerational cultural phylum" ("Memory" 72). Epiphylogenetic memory is 
for Stiegler what determines the human as human. Particular examples of such memory are thereby nonliving exteriorizations of the interior epigenetic experience of the living individual, ${ }^{6}$ or "the pursuit of the evolution of the living by other means than life" (Technics and Time Vol. 1, $135)$.

For Stiegler, human beings always live in relation to the past, not only their own past but also the past of the world in which they find themselves, "this past that I have never lived but that is nevertheless my past, without which I never would have had any past of my own" (140). The condition for the existence of this past is that "the epigenetic layer of life, far from being lost with the living when it dies, conserves and sediments itself, passes itself down in 'the order of survival' and to posterity as a gift as well as a debt, that is, as a destiny" (140). Epigenetic memory can persist into the future via this process of sedimentation, i.e., the accumulation of epiphylogenetic memory to be preserved for future generations through having been produced by technical processes (in the original Greek sense of techne, art or craft).

According to Stiegler, epiphylogenetic expressions, the exteriorizations of interior epigenetic memory, are fundamentally technical in nature. The history of these expressions and their development is "a history of technics - which is the invention of the human" (136). It is important here to recognize that for Stiegler, human beings do not just invent or produce the series of expressions that make up the history of technics. Rather, technics and the human are codeterminative. As Stiegler states in two grammatically curious sentences, "[t]he technical inventing the human, the human inventing the technical. Technics as inventive as well as invented" (136).

Epiphylogenetic artifacts, then, are nonliving, concrete things which serve as memory supports and thereby as the means by which past experiences, thoughts, ideas, and arguments, to 
name a few examples of epigenetic memories of the individual, are handed down to successive generations of a particular culture. They both determine, and are determined by, the human beings who encounter and produce them. As such, they are examples of what Stiegler calls prostheses. For Stiegler, "[ $[\mathrm{t}]$ he prosthesis is not a mere extension of the human body; it is the constitution of this body qua 'human'” (152-153). Further, as prosthesis, epiphylogenetic memory has a temporal character. This is because prostheses, present to us as things which we manipulate, are "set in advance, already there (past [emphasis added])," as well as comprehended in the context of "anticipation (foresight)" (152) and hence are futurally directed. ${ }^{7}$

This means that for Stiegler, "[t]he question of technics is the question of time" (154). Linking several strands of the above discussion together, Stiegler writes that the question of time is

apprehended on the basis of the techno-logical problematic of artificial memory, always the memory of the human qua already-there. The already-there is the pregiven horizon of time, as the past that is mine but I have nevertheless not lived, to which my sole access is through the traces left of that past. This means that there is no already-there, and therefore no relation to time, without artificial memory supports. The memory of the existence of the generations that preceded me, and without which I would be nothing, is bequeathed on such supports. (159)

The already-there, or, the world into which human beings are born/thrown in Heidegger's terms, is technical at its core. This is because the totality of the already-there has been made through artifice, or techne: "there is time only because memory is 'artificial,' becoming constituted as already-there since its 'having been placed outside of the species"' (172).

We are now prepared to understand hypomnesis as Stiegler defines it properly: "recollection through externalized memory" ("Memory" 67). Hypomnesis is thus the process which the living individual undertakes in order to recollect something, be it a fact, an idea, or an argument, with the support of nonliving epiphylogenetic artifacts, i.e., instantiations of 
externalized memory. We are immediately reminded here of Plato's apparent disparaging of hypomnesis in the Phaedrus, placing it in the orbit of sophistry, in contrast to anamnesis which is related to wisdom and truth. By contrast, as is evident from the above discussion of Stiegler's writings, for Stiegler, as for Derrida, hypomnesis is constitutive of the human as such. This is because it is through the hypomnesic processes of interpreting epiphylogenetic artifacts that human beings come to understand temporality, i.e., through the individual recognizing that particular individual's past as part of, and dependent on, a past greater than itself that, in turn, it did not live. ${ }^{8}$

Stiegler calls the methods by which epiphylogenetic artifacts are produced mnemotechniques, defined as "conscious methods of memory storage" (67). One such mnemotechnique is writing, as it is one of the means by which past epigenetic experiences are preserved or sedimented for the future. The printed book, as produced through this mnemotechnique, is a paradigmatic example of an epiphylogenetic artifact. Further, since the invention of the printing press, the exponential accumulation of printed books has resulted in the need for, and subsequent development of, mnemotechnologies, or "technolog[ies] that systematically organize memories" (67). Stiegler elsewhere calls these the

navigational tools [that] appear that, within the epiphylogenetic horizon that makes it necessary, deal with access to the already-there by delegating the who's authority to whats as orienting instruments in the accumulation of knowledge-library catalogues, indexes, bibliographies, sets of files made possible by the printed book through its serialization, pagination, synopses, tables of contents, glossaries. (Technics and Time Vol. 2, 79)

As the mention of library-specific organizational standards in the above quotation indicates, the library as an institution can be understood as instantiating particular mnemotechnologies. To sum up, we can express the concepts discussed in this section together, identifying what can be called 
a Stieglerian understanding of books and libraries: it can be said that the book is an epiphylogenetic artifact, produced by the mnemotechnique of writing, organized in the library in accordance with mnemotechnologies of cataloguing, subject classification, etc. (i.e., the standards of librarianship as most of the planet currently practices them), and accessed through reading, a process of hypomnesis.

One of Stiegler's strongest critiques of Heidegger is his lack of recognition of the inherent technicity of the handing down of the past to the individual, of which one method is the library and the books within it. Speaking specifically about Being and Time, Stiegler states that

[i]f 'the resoluteness which comes back to itself' is the 'authentic repetition of a possibility of existence that has been-the possibility that Dasein may choose its hero'..., if that is indeed the consequence of having a past that is not mine (that I have not lived, but without which my past is nothing), then such a repetition can only make sense for itself within an epiphylogenetic horizon, each time singular in that it is shot through by the dynamic of a what - or a tertiary memory from which the who can never disengage itself. (Technics and Time Vol. 2, 270).

In Being and Time, Heidegger outlines what Stiegler calls a "structure of inheritance," one that starts "from the analysis of the world as the world of objects [and] which forms, at the heart of the system of referring, what he calls the already-there of historicality, of Geschichtlichkeit" (Stiegler, "Technics of Decision" 157-158). The problem, implicit in Stiegler's work discussed above, is made explicit: in his analysis of the structure of inheritance, "Heidegger does not raise the question here of the actual conditions of this inheritance, inasmuch as they are already inscribed in its originary technicity" (158). It is therefore to Being and Time that we now turn, in order to outline this structure of inheritance and thereby both to recognize the purchase of Stiegler's critique more clearly, and, more generally, to contrast the above Stieglerian conception of the book and the library with Heideggerian ones. 


\section{The Book as "Fated Equipment:" Being and Time}

In order to undertake the task of this paper we must examine several concepts used in Being and Time (1927), my goal being to outline a conception of books and libraries in accordance with the analyses found there and to compare that conception to Stiegler's. To begin, books, understood as things Dasein (the "entity which each of us is himself" (Heidegger, Being and Time 27) encounters in the context of its everyday existence, can be seen as examples of equipment (das Zeug) (97). Equipment is always encountered as part of a system or "totality" of things that are oriented towards one of Dasein's further practical considerations, or what Heidegger calls that thing's "in-order-to $[u m-z u]$ " (97). For Heidegger, the totality of things embedded in the structure of this in-order-to can extend even to places. For example, a room and its contents (e.g., a library) is understood as existing in order to serve the purposes of whatever the larger totality of which the room is a part is deigned to accomplish (97-98). Individual things (e.g., books) emerge from, or become distinct as things in light of, this totality as manipulable things, but always in reference to the totality. Heidegger calls the form of existing, or Being, of these individual things "readiness-to-hand [Zuhandenheit]" (98), in the sense that they are there ready to be used for Dasein's projects. It is important to note that readiness-to-hand is "the kind of Being characteristic of those entities which are proximally discovered within-the-world" (101).

Next, Dasein has the existential character of "Being-ahead-of-itself [Vorwegsein]," in the sense that it "has already compared itself, in its Being, with a possibility of itself" (236). This futural orientation of Dasein toward its own possibilities is for Heidegger a fundamental aspect of human existence. However, equally fundamental is thrownness (Geworfenheit), or Dasein's "facticity of its being delivered over" (174). Dasein always already finds itself thrown into its 
world at any particular moment, while at the same time oriented toward its own possibilities. This structure maps on to Dasein's quality of temporality: having been thrown into a world at some past moment, finding oneself as thrown in the present, and oriented toward the future possibilities determined by that thrownness.

Heidegger connects the concept of readiness-to-hand and the tripartite temporal structure of Dasein through the concept of care (Sorge). Care is for Heidegger the meaning of Dasein's Being and is elaborated thusly: "[t]he Being of Dasein means ahead-of-itself-Being-already-in(the-world) as Being-alongside (entities encountered within-the-world)" (237). As thrown into a world, we are also surrounded by things embedded within the systems and structures of that world, which in turn define those things as existing in order to accomplish something. We again return to the examples of the book and the library. Conceived within this framework, the book is encountered as equipment within the systemic totality of the library, which itself is grasped in its Being as place or site determined by the context of Dasein's possibilities. In light of Stiegler's criticisms, however, the question of the technological basis of these possibilities, i.e., how Dasein can receive them as its possibilities, must then be raised.

In section 74 of Being and Time, titled "The Basic Constitution of Historicality," Heidegger states plainly that "[c]are is grounded in temporality" (434). Now, part of Dasein's temporal structure is that, in considering its possibilities, Dasein projects (entwerfen) ${ }^{9}$ itself into the future in accordance with those possibilities. This is not to say that Dasein begins from a particular position and then plans in accordance with some future goal; rather, "Dasein has, as Dasein, already projected itself; and as long as it is, it is projecting. As long as it is, Dasein always has understood itself and always will understand itself in terms of possibilities" (185). Heidegger adds the necessity of resoluteness in order to project in an authentic manner: Dasein 
recognizes its possibilities as its own and no one else's, thereby permitting Dasein to affirm those possibilities resolutely (314). Heidegger then adds to resoluteness the concept of anticipation. Anticipatory resoluteness is recognition of the fact that all of Dasein's possibilities end in death, or the cessation of Dasein. Death, for Heidegger, is "a possibility-of-Being which Dasein has to take over in every case. With death, Dasein stands before itself in its ownmost potentiality-forBeing” (294).

Dasein's confrontation with death, i.e., the recognition that all possibilities end in Dasein's exit from the world or from Being, in fact permits recognition of those possibilities authentically. Heidegger describes resoluteness as that "in which Dasein comes back to itself, discloses current factical possibilities of authentic existing, and discloses them in terms of the heritage which that resoluteness, as thrown, takes over" (435). Dasein's recognition of its own death, i.e., that all possibilities of existence end with the particular death that only Dasein may experience, is what gives those possibilities their authenticity. Dasein inherits its possibilities, or, echoing Stiegler, lives out of and in accordance with a past that is not its own. The past as a source of possibilities, including the meaning of all of the equipment and structures which make up the world into which Dasein is thrown, is handed down (überliefern) to Dasein by Dasein itself. Through living out those possibilities that Dasein has handed down to itself, it can thus repeat past possibilities of its heritage, even in novel ways, i.e., "not necessarily as having thus come down" (435). It is through anticipatory resolution, Dasein's acknowledgement that all possibilities end in death and choosing from amongst those possibilities in light of that fact, that permits Dasein to be brought "into the simplicity of its fate [Schicksal]" (435). Dasein is fated to live in light of the past which it has inherited and yet is not its own. It is precisely here that Stiegler's critique applies: there is no discussion in Being and Time of the medium of 
inheritance, or handing down, as itself being dependent upon epiphylogenetic technical artifacts. "Repeating" of possibilities of one's historicality "is handing down explicitly—that is to say, going back into the possibilities of the Dasein that has-been-there" (437) i.e., the epigenetic memory of past lives led and the ideas developed therein, expressed through mnemotechniques (e.g., writing) and encountered via hypomnesis (e.g., reading).

In this way, Heidegger's thinking can be supplemented via Stiegler's critique, in the sense that providing an examination of the inherently technological character of the artifacts necessary for the transmission of Dasein's possibilities would permit a more accurate analysis of the structures of experience that Heidegger wishes to conceptualize in Being and Time. If Stiegler's critique is accurate, Heidegger's concept of the structure of Dasein's inheritance of its possibilities must include an analysis of the technical means of that inheritance.

It should be noted here that Heidegger does mention books in Being and Time, in precisely one location. In the section immediately following the one just discussed, Heidegger notes that "[e]quipment and work-for instance, books — have their fates [Schicksale]" (440). It is unclear what this could mean, as the previous section seemed to imply that Heidegger intended fate only to apply to Dasein, whose Being is entirely different from the equipment surrounding it. One possible interpretation is that, as equipment, books are thereby determined as part of the existential structure of fated Dasein itself. Regardless, at no point in the text does Heidegger confront the technical character of books or libraries. More explicit mentions of both are to be found in his later writings, however, and it is to these later works that we now turn. 


\section{The Modern Book and the Modern Library: "The Age of the World Picture" and "The Question Concerning Technology"}

"The Age of the World Picture" is a 1938 essay and therefore firmly the product of what has been called Heidegger's post-Kehre period. Heidegger himself states that around the time of the delivery of the lecture "On the Essence of Truth" in 1930, his work took a marked turn (Kehre) (Heidegger, "Letter on 'Humanism"” 250). ${ }^{10}$ Heidegger writes in "The Age of the World Picture" that the modern epoch is characterized by human beings considered to be "that being upon which all that is, is grounded as regards the manner of its Being and its truth" (128). ${ }^{11}$ This means that the world is grasped as an object, in contradistinction to "the primary and only real subiectum" (128), humanity. The defining parameters of the world as this object are, for Heidegger, delimited by specifically modern science beginning with Descartes (127). ${ }^{12}$

The library as it is conceived in the modern epoch can be considered as a symptom of the age of the world picture. Heidegger distinguishes between two types of what we would call academics or intellectuals, namely the scholar and the research man. These types arise in accordance with "the modern character of science as ongoing activity" (125). In the modern age,

[t]he scholar disappears. He is succeeded by the research man who is engaged in research projects. These, rather than the cultivating of erudition, lend to his work its atmosphere of incisiveness. The research man no longer needs a library at home. Moreover, he is constantly on the move. He negotiates at meetings and collects information at congresses. He contracts for commissions with book publishers. The latter now determine along with him which books must be written. (125, my italics)

Heidegger here is criticizing the modern age's obsession with the new, the fresh, the incisive, at the potential loss of the possibility of "creative questioning and shaping out of the power of genuine reflection [Besinnung]" (136). As the paradigmatic case of the human investigator into what is of this era, the research man no longer needs a home library. This statement can be interpreted in at least three ways. First, the intended critique may be that the research man no 
longer needs to read the classical works of the past in order to be successful at research, or at least no longer needs to have them at hand for consultation. This is because the works of the past, as past, would be from the perspective of the research man lacking in present-oriented incisiveness. Second, and perhaps more telling, it is likely that Heidegger experienced the rapid growth of the modern library as an institution, both academic and public, in his lifetime. Hence, there may be an element of critique directed against that institution itself: if the library's collection is not carefully chosen by the scholar, the content of the library will be subject to the whims of modernity, i.e., its content will be determined by those responsible for which books are written, research men and their publishers. The third possibility is that, as not 'at-home,' the modern library is instead a receptacle or depot wherein books are stored, waiting to be accessed (as standing-reserve, perhaps?), rather than things in the world to be comprehended poetically and hence 'dwelled with. ${ }^{13}$ This may mean that in his statement on libraries, Heidegger is prefiguring the argument concerning the totalizing power of modern technology, Enframing, several years before explicitly identifying this concept in "The Question Concerning Technology." The statement, however, remains ambiguous.

Held under the sway of modernity's picture of the world, the modern researcher, in the attempt to appear timely, no longer works out of /in response to the particular historical tradition into which the researcher is thrown. The modern researcher no longer needs a basis in the past from which to work in the present. According to Heidegger, in the modern age there is only the present, only the new. In a further elaboration of the role of books in the modern age, Heidegger claims that their specifically modern form, "[t]he preponderance of collections, of sets of books, of series and pocket editions" (139), is again a symptom of holding humanity to be the ground of any and all understandings of Being. This is because modern books are part of "a procedure that 
plans and establishes itself with a view to the way in which, through the prearranged and limited publication of books and periodicals, they are to bring the world into the picture for the public and confirm it publically" (139). The modern book is thus for Heidegger the means of publically disseminating the notion of humanity as the primary and only subiectum, hence perpetuating the age of the world picture. This tendency dovetails with the aims of modern researchers, for the modern form of the book permits those researchers "not only [to be] acknowledged and given consideration more easily and more rapidly...but, reaching a wider public, they immediately achieve their intended effect" (139).

Viewed from Stiegler's perspective, Heidegger would seem to be on the right track in noting the technological character of books and libraries, and how that technological character then influences humanity's existence. At first blush, this seems similar to Stiegler's claim that epiphylogenetic artifacts and human beings are codeterminative of each other. However, Heidegger does not recognize that this occurrence is not just an aspect particular to the modern age. Rather, implicitly repeating at least the formal structure of Plato's condemnation of writing in the Phaedrus, Heidegger seems to be criticizing the contemporary dependence on what can be seen as the modern version of hypomnesic technics, modern books and libraries. The scholar, conversely, has no need of a public library due to having a privately-curated coterie of books in the scholar's possession; the scholar is at-home in her library. Heidegger's position neglects the inherent technical character of all books as epiphylogenetic artifacts, however. Stiegler's critique again provides a useful supplement to Heidegger's thought here.

Heidegger's concern with technology as a concept, one that will receive greater attention later in his life, is hinted at in "The Age of the World Picture:" "[t]he research worker necessarily presses forward of himself into the sphere characteristic of the technologist in the essential sense. 
Only in this way is he capable of acting effectively, and only thus, after the matter of his age, is he real" (125). Let us now turn to "The Question Concerning Technology," where Heidegger further elaborates on the power of the sphere of technology to close off any possible understanding of Being other than that which technology reveals.

The most important lesson of Heidegger's essay, originally published in Vorträge und Aufsätze in 1954, is that, instead of a thing to be manipulated or controlled, "[t]echnology is a mode of revealing" ("Technology" 13). Things in the world are revealed in their Being as such via technology, or more precisely, in the modern era, beings are understood in their Being as first and foremost technological. For Heidegger, "[t]he revealing that rules in modern technology is a challenging, which puts to nature the unreasonable demand that it supply energy that can be extracted and stored as such" (14). For Heidegger, modern books and libraries must therefore be symptomatic of this process: the modern method of book production, storage, and access via libraries are particular examples of modern technology, and as such instantiate the essential character of technology as a way of revealing. Technology's way of revealing results in "[e]verywhere everything [being] ordered to stand by, to be immediately at hand, indeed to stand there just so that it may be on call for a further ordering. Whatever is ordered about in this way has its own standing. We call it the standing-reserve [Bestand]." (17) For Heidegger, an illustrative example of standing-reserve is a hydroelectric dam placed on a river. Heidegger contrasts the Rhine understood as an energy source, ordered to give up its hydroelectric energy on demand, with the Rhine understood through artistic expression, the paradigmatic example being the hymn named after the river by Hölderlin (16). Is it then possible to interpret the books held in a library in this way? Heidegger mentions the modern techniques of printing, which are associated with "a set configuration of opinion [that] becomes available on demand" (18, my 
italics). This configuration of information, available in books and newspapers of the modern age, would then be available for access in the library as a public institution. Heidegger here seems to repeat his condemnation of modern books and publishing found in "The Age of the World Picture."

Continuing, the essence of modern technology, as a mode of revealing, is dangerous for Heidegger, as it has the potential power to close off all other possible modes of revealing. Drawing together and defining the world, the things within it, and humanity itself, modern technology thus has the character of Enframing (Gestell). ${ }^{14}$ Heidegger elaborates: "[i]n Enframing, that unconcealment [or aletheia, or ways of revealing] comes to pass in conformity with which the work of modern technology reveals the real as standing-reserve" (19). It thus seems that modern technology's way of revealing, Enframing, closes off access to possibilities of human existence formerly transmitted via the past that human beings inherit. All that is left in the world is standing-reserve. ${ }^{15}$ This in turn means that the modern book and the modern library must themselves be symptomatic of the modern epoch as the age of Enframing. The content of the modern book and library_-dependent as they are on the modern technology of printing, not to mention (as Stiegler claims) modern techniques of classification and cataloguing in order to provide access to the content of library materials - are endemic of the modern age and thus hold no hope of renewing a relation to the past such that it can be seen as a source of repeatable possibilities of the heritage of a people.

In what way, then, can Enframing be confronted? For Heidegger, this "must happen in a realm that is, on the one hand, akin to the essence of technology and, on the other, fundamentally different from it. Such a realm is art" (35). Art is akin to the essence of technology in the sense that it is one way of revealing beings in their Being, but is fundamentally different in that it 
"brings the true into the splendor," i.e., it lets beings reveal their Being - that which "shines forth most purely" (34). Art, as much as modern technology, reveals beings in a particular way. It is only through the encounter with and comprehension of works of art (in the Heideggerian sense of artwork) ${ }^{16}$ that the essence of modern technology, Enframing, can be properly understood as a revealing of the meaning of Being. This encounter and comprehension prepares the way for Enframing's possible overcoming or circumvention. However, viewing Heidegger's thought from a Stieglerian perspective, Heidegger misses the fact that expressions of, e.g., poetry, disseminated as books printed in a particular language, must themselves be understood as epiphylogenetic artifacts. Further, if these expressions of poetry take the form of books found in libraries, they are organized for access in accordance with the mnemotechnologies used in librarianship. Writing, printing, book production, and library organization are all part of the structure of epiphylogenesis, and the modern book and library, understood in this way, are therefore external memory supports as much as the piece of flint, the cave painting, the papyrus scrolls of Heraclitus, the Gutenberg Bible, the modern newspaper, the early $20^{\text {th }}$-century editions of Hölderlin's poetry, and Heidegger's writings themselves.

I have shown in the above discussion that Heidegger does not acknowledge the technological character of not just modern, but all books and libraries, including those of the preSocratics, such as they were. If this is the case, Heidegger's claim that art and technology are at least conceptually separate or separable in the modern age becomes problematic. The means of transmission of artistic efforts of any kind has always been technological in character; the modern means is simply a new iteration of this character. The modern book and library, for Heidegger, are symptomatic of Enframing. However, according to Stiegler, the modern book is a nonliving epiphylogenetic artifact external to living human memory. A fundamentally technical 
artifact serves as the necessary 'site' in which to carry out a Heideggerian confrontation with Enframing, at least at this particular historical moment. Again, much like the suggestion made at the end of my discussion of Being and Time above, it is crucial to carry out a consideration of the specific technical character of books in relation to the later Heidegger's thought. It is hoped, then, that the above discussion of Heidegger's writings, in light of Stiegler's critique, is enough to indicate how Heidegger's thought can be supplemented in order for it to be more accurate to the phenomena it purports to describe.

\section{Concluding Remarks: 'Dead Memories' in Cloud Atlas}

The argument developed throughout this paper used the book and the library as exemplary aspects of the process of epiphylogenesis, in order to highlight how Stiegler's critique of Heidegger can supplement Heidegger's thinking in a concrete way. I wish to conclude with some remarks on one aspect of this critique, namely Stiegler's response to Heidegger's conception of death in Being and Time,${ }^{17}$ as well as outline one possible site of confrontation with the essence of modern technology, i.e. a poetic work of art, through consideration of a particular artwork, the novel Cloud Atlas.

As was mentioned above, in Being and Time Heidegger considers death, or the cessation of Dasein, to be an integral part of Dasein's existential structure. Dasein must confront and appropriate its own death in order to exist authentically, or, for the purposes of this paper, to acknowledge 'properly" ${ }^{18}$ that heritage which is handed down to Dasein in an authentic way. However, for Stiegler, it is not just authentic Dasein that has a relation to death: "one must in all rigour speak of mortality as soon as there is exteriorization and prosthesis" (Stiegler, Technics and Time Vol. 1, 130). This means that every moment of exteriorization involves death, or dead 
matter, organized in order to permit epigenetic memory content to persist into the future. This is what it means to undertake the pursuit of life by means other than life. Stiegler notes that it is Derrida who “exposes and undermines Plato's attempt to oppose interior memory and its exterior traces: it is impossible to oppose living memory to externalized, dead memory (hypomnematon) since externalized memory, as supplement, constitutes living memory as knowable" ("Memory" 69). For Stiegler, dead matter, organized as epiphylogenetic memory supplements, constitutes living epigenetic memory. Human memory must be rethought, contra Derrida's and Stiegler's Plato, "as a process of grammatization in which living and dead compose without end" (72). ${ }^{19}$

This means that human beings are quite literally haunted by the spirits of the past, as expressed through the dead matter which serves as the substrate for those spirits' previously living epigenetic memory. As Stiegler states, this haunting "means that I am an heir, that fundamentally my past is not my past: it is the past of a culture that I inherit ... the past of the dead. I am always already haunted by the dead, through the objects that they leave to me, mostly anonymously" (“Technics of Decision” 158). A brief discussion of the novel Cloud Atlas-both in structure and in content an excellent example of the Stieglerian complex of epiphylogenesismnemotechnique-hypomnesis ${ }^{20}$ - will illustrate one possible method of how the inheritance of memory is carried out through technological artifacts.

The novel itself is made up of 11 chapters, each appearing in the narrative arc of the novel as a particular type of media: handwritten journal, series of handwritten letters, novel, film, and even holographic projection, only to return to spoken narrative, specifically the telling of a story around a campfire, in the central chapter. Each chapter is also written in the style of a particular definable genre: travel writing, Gothic novel, thriller, broad comedy, and two forms of science fiction defined by the common sci-fi tropes of the problems inherent in the rise of 
artificial intelligence and the world after an apocalyptic event, respectively. In the narrative, the first chapter is encountered as a document by a character in the second chapter, the second as a document in the third, and so forth until the sixth chapter. After this chapter, the order reverses, and the reader of Mitchell's novel passes through the conclusions of each story until finally arriving where she began, with the conclusion of the first chapter of the book.

Through its focus on epiphylogenetic technical artifacts (journals, novels, holographic projections) and how those artifacts are encountered and processed in the course of the narrative, Cloud Atlas can be seen as instantiating via fiction Stielger's epiphylogenesis-mnemotechniquehypomnesis complex. The first work, the travel journal, is an epiphylogenetic artifact produced via writing, i.e., a mnemotechnique. The journal is then encountered in the second chapter via the particular character's reading the journal, i.e., an act of hypomnesis. This pattern repeats throughout the remaining chapters up to the central one, recited in speech as a story around a campfire, whereupon the pattern reverses.

Speaking specifically of the content of the novel, each character is spurred to action either through their search for or their encounter with the epiphylogenetic artifactual record of a character's life in the previous chapter. This encounter, according to Stiegler (echoing the sentiment if not the argument of Being and Time), is the way in which we receive our heritage, the source of possibilities, inscribed in dead matter, from which we living humans draw. Each character, it should also be noted, is not alive in the story in which his or her particular epiphylogenetic artifact appears, as each chapter moves the narrative significantly forward (and, after the central chapter, backward) in time. The novel's content also shows that the actions of the main character in the central sixth chapter, the one furthest in time from the first, directly result from the transmission and preservation of the epigenetic memories of the first chapter's the 
main character. Both the content and the structure of the novel can be considered as a paradigmatic demonstration of Stieglerian theory. Taking the Stieglerian analysis even further, my reading the novel itself can be understood as a hypomnesic encounter with author David Mitchell's epigenetic memory in epiphylogenetic form, produced through the mnemotechnique of writing and the mnemotechnology of printing. Mitchell's thoughts and ideas are accessible via the reader's encounter with the text, and this accessibility will persist long after Mitchell the author is no longer living. The act of reading the novel, of having it in one's hands, provokes this construal.

It is hoped that the brief discussion above shows how Cloud Atlas can serve both as a means by which to approach, and an illustrative example of, Stiegler's philosophical concepts. Indeed, much as the characters in the novel, from Stiegler's perspective we are perpetually haunted by spirits, spirits which - in this case through the specific technology of the 'dead matter' of the printed word-seem to find no discussion in Heidegger's work. And yet, in considering Cloud Atlas, we may follow Heidegger's advice, if not his direction, through taking the site of confrontation with the essence of modern technology to be that of art. To conclude, then, death and dead memories haunt Heidegger, Stiegler, and the characters of Cloud Atlas, and yet those memories remain, for them and for us, the 'other means' in accordance with which life continues to evolve. 


\section{Notes}

1 In this paper, by 'the book' I mean the traditional printed codex. I will not discuss the increasingly prevalent digitization and subsequent electronic form of library holdings which itself may change the essential character of the library and of the book themselves. That work, much broader in scope, would require more than the space limitations of this paper permit. Regardless, it is useful to read Albert Borgmann's work to understand something of the difference between the library as book repository and its current, digital variant: "The inherent fluidity and facility of information technology may move us to consider a radically different way of presenting information, some method of selecting, stabilizing, and secluding information so that it will invite quiet attention, and a manner of making it spare and austere enough to engage memory and imagination. We may find a new regard for an old vessel of information - the book. And when we have recovered the book, we may want to restore the place that used to be dedicated to the quietude and concentration the book inspires - the library" (Borgmann 212). On the distinction between "library culture" and "information-retrieval culture," see the chart based on Terry Winograd's work found in Dreyfus and Spinosa (164).

${ }^{2}$ I will not discuss other specific technological examples which may also serve as means by which an individual may come to know the thoughts of those who came before, e.g., sound recording devices, film, and so forth. A discussion of other kinds of technological artifacts related to historically-transmitted memory must be left for future research.

3 See Pieter Lemmens's interview with Stiegler (37) for a discussion of Plato and book production.

4 This gives evidence that even in this short passage on writing, Plato is asserting his oftattributed maxim of the difference between opinion and knowledge.

5 This is not necessarily to say that Derrida and Stiegler present a 'unified front' against Plato. While similar in many respects, Derrida and Stiegler do diverge. For example, the notion of inheritance, central for this paper's discussion on Heidegger, marks such a point of divergence: "[f]or both Stiegler and Derrida the question of technics is closely linked to the question of inheritance: for Stiegler ... it is because the technical object is the condition of my access to the 'past I have not lived' that technics is constitutive of temporality; for Derrida, 'to be is to inherit,' that is, to be is to be inhabited by a certain spectral inheritance" (Roberts, "Stiegler Reading Derrida" para. 16). The difference, while subtle, is remarkable: it means that Derrida believes all things to share or participate in an identical way of Being ('to inherit'); for Stiegler, conversely, human beings, as inheritors of their past, are thereby distinct among beings more generally, thus permitting something of an 'ontological difference' not necessarily present in Derrida.

${ }^{6}$ Here we may note that Stiegler's thought is at least structurally an echo of his teacher's. In the midst of defining his concept of the trace in Of Grammatology, Derrida writes that the trace is itself the "arche-phenomenon of "memory" and is "the opening of the first exteriority in general, the enigmatic relationship of the living to its other and of an inside to an outside" (70). Further, 
exteriority can only arise via "the nonpresence of the other inscribed within the sense of the present, without the relationship with death as the concrete structure of the living present" (71). While I certainly do not wish to conflate the concepts of the Derridean trace and the Stieglerian epiphylogenetic memory, they certainly share many common features.

${ }^{7}$ From Stiegler's language, once could plausibly conclude that prostheses, including particular instantiations of epiphylogenetic memory, are instantiating or echoing the threefold structure of temporalization which Heidegger develops in Being and Time.

${ }^{8}$ As Patrick Crogan writes, "[n]o cultural transmission, or innovation, no historical, political, or philosophical reflection takes place without [the] recording of the experience of past lives that I/we have not ourselves lived" (Crogan 140).

9 The etymological, and hence for Heidegger conceptual, relation between thrownness (Geworfenheit) and projecting (entwerfen) and projection (Entwurf) is lost in English translation.

${ }^{10}$ In this paper, I do not wish to discuss the many issues surrounding the possible reorientation in Heidegger's thought. Rather, in classifying Heidegger's writings under scrutiny here as 'early' and 'later,' I merely wish to note how Stiegler's critique applies to writings from various moments in Heidegger's corpus.

11 This seems to imply that Being and Time can be criticized from this perspective. Were not things encountered in the world understood in their Being in the context of Dasein's projects? However, holding this critique is to forget that Dasein itself is a particular mode of Being, one which human beings instantiate, and central to this mode of Being is that its content is that of possibilities that it has inherited or handed down to itself. This means that Dasein's projects do not originate in Dasein. Dasein is a focal point of several codeterminative structures of Being, and to call it simply 'the human' is to miss the point.

12 "[S]cience, as Heidegger sees it, does not merely construe its set of propositions as a picture of the world. It does something much more emphatic. It decides, in a normative fashion, that the world itself consists in nothing other than the picture drawn by science" (Alderman 37).

${ }^{13}$ I am grateful to Darin Barney for pointing out this potential third reading to me.

${ }^{14}$ Heidegger here seems to have moved away from the human-centred position he held in "The Age of the World Picture," as human beings are no longer subiectum but are themselves drawn together into, and hence defined by, the structure of modern technology's Enframing. This shift is discussed in further detail in Dreyfus and Spinosa 160-161. 
15 "Bestand is meant to contrast with Gegenstand, object, that which stands over against. Strictly speaking, for modern technology there are no objects. There is only a vast pool of stable reserves" (Lovitt 50).

16 In "Origin of the Work of Art," Heidegger defines art as "the letting happen of the truth of beings" (44, my emphasis). The highest art, for Heidegger, lets beings reveal the truth of their Being, as opposed to Enframing which challenges beings to reveal the truth of their Being as standing-reserve. Art and modern technology are essentially akin, however, in that they reveal the truth of the Being of beings.

${ }^{17}$ Much of Stiegler's current output is concerned with the political consequences to be drawn from his conception of technics. This can be seen from the following passage: "the community acknowledged that it was nothing but its memory, that this instrumentalization itself could be the subject of decisions, and that a politics of memory always and completely determines a community's future" (Technics and Time Vol. 2, 146). In this regard Stiegler's work can be related with Foucault's and Agamben's respective writings on biopolitics.

${ }^{18}$ I here use the second, less obvious sense of proper, that of one's own expressed by the French propre and German eigen. Dasein must make its heritage its own in order to be able to repeat the possibilities of that heritage authentically. It does this through confrontation with its own death.

19 "When life becomes externalized into technical materiality, the possibility of a constitutive trans-individual memory, of history and tradition, is first opened. This external technical materiality is both the means for preserving memory beyond the death of the individual and equally the medium via which life is first articulated by a relation to death" (Colony 80).

20 The philosophical richness of the novel is multifaceted. In addition to resonance with Stiegler's work, the novel also echoes the concepts of the Buddhist samsara as well as the Nietzschean eternal return, not to mention the fictional works of Mary Shelley, Herman Melville, William S. Burroughs, and others. For a discussion of the concept of eternal return in Cloud Atlas, see Hicks; for a discussion of the relation between Mitchell's writing and that of other literary figures, see Economides.

\section{Works Cited}

Alderman, Harold. "Heidegger's Critique of Science and Technology." Heidegger and Modern Philosophy. Ed. Michael Murray. New Haven, CT: Yale University Press, 1978. Print.

Borgmann, Albert. Holding On to Reality: The Nature of Information at the Turn of the Millennium. Chicago, IL: University of Chicago Press, 1999. Print. 
Colony, Tracy. "Epimetheus Bound: Stiegler on Derrida, Life, and the Technological Condition.” Research in Phenomenology 41 (2011): 72-89. Print.

Crogan, Patrick. "Bernard Stiegler: Philosophy, Technics, and Activism." Cultural Politics 6.2 (2010): 133-156. Web. 1 Dec. 2012

Derrida, Jacques. Of Grammatology. Trans. Gayatri Chakravorty Spivak. Baltimore, MD and London, UK: Johns Hopkins University Press, 1997. Print.

—. Dissemination. Trans. Barbara Johnson. Chicago, IL: University of Chicago Press, 1981. Print.

Dreyfus, Hubert and Charles Spinosa, "Highway Bridges and Feasts: Heidegger and Borgmann on How to Affirm Technology." Man and World 30 (1997): 159-177. Web. 1 Dec. 2012.

Economides, Louise. "Recycled Creatures and Rogue Genomes: Biotechnology in Mary Shelley's Frankenstein and David Mitchell's Cloud Atlas." Literature Compass 6.3 (2009): 615631. Print.

Heidegger, Martin. "The Age of the World Picture." The Question Concerning Technology and Other Essays. Trans. William Lovitt. New York, NY: Harper and Row, 1977. Print.

—. Being and Time. Trans. John Macquarrie and Edward Robinson. New York, NY: Harper and Row, 1962. Print.

—. "Letter on 'Humanism." Trans. Frank A. Capuzzi. Pathmarks. Ed. William McNeill. Cambridge, UK: Cambridge University Press, 1998. Print.

-. "Origin of the Work of Art." Off the Beaten Track. Ed. and trans. Julian Young and Kenneth Haynes. Cambridge, UK: Cambridge University Press, 2002. Print.

- Plato's Sophist. Trans. Richard Rojcewicz and Andre Shuwer. Bloomington, IN: Indiana University Press, 1997. Print.

—. "The Question Concerning Technology." The Question Concerning Technology and Other Essays. Trans. William Lovitt. New York, NY: Harper and Row, 1977. Print.

Hicks, Heather J. “"This Time Round:' David Mitchell's Cloud Atlas and the Apocalyptic Problem of Historicism.” Postmodern Culture 20.3 (2010). Web. 1 December 2012.

Lemmens, Pieter. “'This System Does Not Produce Pleasure Anymore:' An Interview with Bernard Stiegler.” Krisis 1 (2011): 33-41. Web. 1 Dec. 2012. 
Lovitt, William. "A Gesprach with Heidegger on Technology." Man and World 6.1 (1973): 4462. Print.

Mitchell, David. Cloud Atlas. Toronto, ON: Vintage Canada, 2004. Print.

Plato. Phaedrus. Trans. Robin Waterfield. Oxford, UK: Oxford University Press, 2002. Web. 1 Dec. 2012.

Roberts, Ben. "Stiegler Reading Derrida: The Prosthesis of Deconstruction in Technics." Postmodern Culture 16.1 (2005): 37 paras. Web. 1 Dec. 2012.

Stiegler, Bernard. "Memory." Critical Terms for Media Studies. Ed. W. J. T. Mitchell and Mark B. N. Hansen. Chicago: University of Chicago Press, 2010. Print.

- Technics and Time, Vol. 1: The Fault of Epimetheus. Trans. Richard Beardsworth and George Collins. Stanford, CA: Stanford University Press, 1998. Print.

-. Technics and Time, Vol. 2: Disorientation. Trans. Stephen Barker. Stanford, CA: Stanford University Press, 2009. Print.

—. “Technics of Decision: An Interview." Trans. Sean Gaston. Angelaki 8.2 (2003): 151- 167. Web. 1 Dec. 2012. 